\title{
Serum GRP78 as a Tumor Marker and Its Prognostic Significance in Non-Small Cell Lung Cancers: A Retrospective Study
}

\author{
Xiao Ma, ${ }^{1,2}$ Wei Guo, ${ }^{1,2}$ Su Yang, Xiaoli Zhu, ${ }^{3,4}$ Jiaqing Xiang, ${ }^{1,2}$ and Hecheng $\mathrm{Li}^{5}$ \\ ${ }^{1}$ Department of Thoracic Surgery, Fudan University Shanghai Cancer Center, Shanghai, China \\ ${ }^{2}$ Department of Oncology, Shanghai Medical College, Fudan University, Shanghai 200032, China \\ ${ }^{3}$ Department of Thoracic Surgery, Nanjing Chest Hospital, Nanjing 210029, China \\ ${ }^{4}$ Department of Pathology, Fudan University Shanghai Cancer Center, Shanghai 200032, China \\ ${ }^{5}$ Department of Thoracic Surgery, Ruijin Hospital, Shanghai Jiaotong University School of Medicine, Shanghai 200025, China
}

Correspondence should be addressed to Hecheng Li; lihecheng2000@hotmail.com

Received 17 March 2015; Accepted 19 May 2015

Academic Editor: Ralf Lichtinghagen

Copyright (C) 2015 Xiao Ma et al. This is an open access article distributed under the Creative Commons Attribution License, which permits unrestricted use, distribution, and reproduction in any medium, provided the original work is properly cited.

\begin{abstract}
Introduction. Glucose-regulated protein 78 (78 kDa, GRP78), which is also known as immunoglobulin heavy chain binding protein (BIP), is a major chaperone in the endoplasmic reticulum (ER). The expression and clinical significance of GRP78 in the serum of non-small cell lung cancer patients have not yet been clearly described. The aims of the present study were to investigate the expression of GRP78 in the serum of non-small cell lung cancer patients, the relationships with clinicopathological parameters, and the potential implications for survival. Patients and Methods. A total of 163 peripheral blood samples from non-small cell lung cancer patients were prospectively collected at the Department of Thoracic Surgery, Fudan University Shanghai Cancer, China. Clinical characteristics data, including age, gender, stage, overall survival (OS) time, and relapse-free survival (RFS) time, were also collected. Serum GRP78 levels were measured using a commercially available ELISA kit. The associations between GRP78 levels and clinicopathological characteristics and survival were examined using Student's $t$-test, Kaplan-Meier, or Cox regression analyses. Results. The mean \pm standard error (SE) value of GRP78 was $326.5 \pm 49.77 \mathrm{pg} / \mathrm{mL}$. This level was significantly lower compared with the level in late-stage non-small cell lung cancer patients $(1227 \pm 223.6, p=0.0001)$. There were no significant correlations with the clinicopathological parameters. No significant difference was found between high GRP78 expression and low GRP78 expression with regard to RFS $(p=0.1585)$. However, the OS of patients with higher GRP78 expression was significantly poorer $(p=0.0334)$. Conclusions. GRP78 was expressed in non-small cell lung cancer patients and was highly enriched in late-stage lung cancer. GRP78 may have an important role in the carcinogenesis of non-small cell lung cancer and may be a prognostic marker for non-small cell lung cancer.
\end{abstract}

\section{Background}

Lung cancer remains the leading cause of cancer-related deaths worldwide. Despite improved multidisciplinary treatments, the overall 5-year survival rate is only approximately $15 \%[1,2]$. Most lung cancer patients have advanced stage disease at diagnosis, which is often associated with metastasis and a poor prognosis [3-5]. More information is needed to predict the prognosis of patients. Molecular diagnostics may offer objective and systematic human cancer classification.
However, the molecular marker standards for human cancers that can be used to predict prognosis have not yet been identified [6].

Glucose-regulated protein 78 (78 kDa, GRP78) is well established as an ER chaperone and widely used as a marker for ER stress [7]. Large amounts of GRP78 were found to be secreted by various tumor cell types [8]. Under stressful conditions such as low glucose, low oxygen, and low calcium ion concentrations, GRP78 is highly expressed for the purpose of maintaining ER stability and cell protection $[9,10]$. GRP78 is 
closely related to carcinogenesis, development, and differentiation $[11,12]$. As a potential marker to predict the prognosis of patients with lung cancer, the expression of serum GRP78 has not yet been clearly described. The clinical significance of GRP78 in patients with non-small cell lung cancer also has not been fully investigated.

With these notions mentioned above, we thus measured the serum GRP78 levels and investigate its predictive value for the prognosis of patients with lung cancer.

\section{Material and Methods}

2.1. Sample Selection. The study protocol was approved by the institutional review board of Fudan University Shanghai Cancer Center, China. Patients with lung cancer who were treated at the cancer center from April 2009 to September 2014 were enrolled in the study. The diagnosis of lung cancer was confirmed using histopathology in the surgical group. Pathological staging was performed according to the TNM classification of the 7th edition of the American Joint Committee for Cancer Staging manual guidelines [13].

2.2. Enzyme-Linked Immunosorbent Assay (ELISA). Peripheral blood ( $5 \mathrm{~mL}$ ) was taken from subjects of each group without the addition of anticoagulant and was allowed to clot for $2 \mathrm{~h}$ at room temperature. Each sample was then centrifuged for $20 \mathrm{~min}$ at $1,000 \times \mathrm{g}$. The serum was separated and stored in small aliquots at $-20^{\circ} \mathrm{C}$ until further protein analysis.

Serum GRP78 levels were measured using a commercially available ELISA Kit (GRP78/BiP ELISA kit, Enzo Life Sciences, ADI-900-214), per the manufacturer's protocol.

2.3. Clinical Variables and Follow-Up. Clinical variables collected included age at diagnosis, gender, tumor differentiation, T stage, and pathologic tumor-node-metastasis (TNM) stage according to the 7th edition of lung cancer staging system [13]. Survival and disease relapse were recorded on the basis of follow-up clinic or telephone. After surgery, 74 patients were followed up in the clinic using chest computed tomography, physical examination, routine blood tests, serum tumor marker tests, brain magnetic resonance imaging, bone scanning, and ultrasonography of the neck and abdomen. Eight patients were lost to follow-up. Follow-up evaluations were performed every 3 months during the first year, every 4 months during the second year, and then every 6 months. The median follow-up period was 22.5 months (range, 3-63 months) for the 74 patients with follow-up records.

2.4. Statistical Analysis. The follow-up period was defined as the time from surgery to the last observation for censored cases, or death for complete observations. Relapse-free survival (RFS) was defined as the time from the date of primary surgery to the date of relapse, or September 2014. Patients without a study end date and who were lost to follow-up were considered censored. The statistical analysis was performed using GraphPad Prism version 5.0 software (Graphpad Software, Inc., California, USA). The unpaired Student's $t$-test was
TABLE 1: Characteristics of lung cancer patients.

\begin{tabular}{lcc}
\hline Parameters & $\begin{array}{c}\text { Early-stage } \\
\text { group } \\
(N=82)\end{array}$ & $\begin{array}{c}\text { Late-stage } \\
\text { group } \\
(N=81)\end{array}$ \\
\hline $\begin{array}{l}\text { Age (years, mean } \pm \text { SD }) \\
\quad \text { (Range) }\end{array}$ & $58.9 \pm 10.2$ & $58.2 \pm 10.0$ \\
Gender & $36-76$ & $34-81$ \\
$\quad$ Male & 51 & 63 \\
Female & 31 & 18 \\
Stage & & \\
I & 38 & - \\
II & 10 & - \\
III & 34 & - \\
IV & - & - \\
Differentiation & & - \\
$\quad$ Well and moderate & 40 & - \\
Poor & 42 & 81 \\
Treatment & & \\
Surgery & 82 & - \\
Chemoradiotherapy/radiotherapy & - & \\
\hline
\end{tabular}

SD: standard deviation.

used for between-group comparisons. Survival curves were plotted using the Kaplan-Meier method. Univariate and multivariate analyses were performed using the Cox proportional hazards model. A two-tailed $p$ value $<0.05$ was considered to be statistically significant.

\section{Results}

3.1. Patient Characteristics. A total of 82 early-stage nonsmall cell lung cancer patients and 81 late-stage non-small cell lung cancer patients were enrolled in this retrospective study. Thirty-one female and 51 male patients were enrolled in the early-stage group $(N=82)$. Eighteen female and 63 male patients were enrolled in late-stage group $(N=81)$. The general characteristics of the subjects that participated in the study are presented in Table 1.

3.2. Detection of Serum GRP78. The mean \pm standard error (SE) GRP78 level was $326.5 \pm 49.77$ in the early-stage lung cancer patients. This level was significantly lower compared with the level in the late-stage lung cancer patients $(p=$ 0.0001).

3.3. Correlation of GRP78 with Various Clinicopathological Factors. The results indicated that there were no significant associations between GRP78 expression and the clinicopathological variables age, gender, pathological $\mathrm{T}$, and pathological stage for the early-stage patients (Table 2).

3.4. Prognostic Factors for Non-Small Cell Lung Cancer Patients. We performed a univariate analysis of the clinicopathological factors to examine the factors that predict 
TABLE 2: Correlation of GRP78 with various clinicopathological factors for early-stage lung cancer patients.

\begin{tabular}{lcc}
\hline Parameters & Mean $(\mathrm{pg} / \mathrm{mL}) \pm \mathrm{SE}$ & $p$ value \\
\hline Age (years) & & \\
$\leq 60$ & $424.8 \pm 82.58$ & 0.0534 \\
$>60$ & & \\
Gender & $313.3 \pm 61.08$ & \\
$\quad$ Male & $348.3 \pm 86.23$ & 0.7350 \\
$\quad$ Female & & \\
pT & $118.91 \pm 426.24$ & \\
T1-T2 & $300.52 \pm 441.76$ & 0.2483 \\
T3 & & \\
Stage & $295.3 \pm 59.96$ & 0.4600 \\
I-II & $370.6 \pm 85.65$ & \\
III & & \\
Differentiation & $363.2 \pm 81.65$ & 0.4755 \\
$\quad$ Well and moderate & $291.6 \pm 58.77$ & \\
$\quad$ Poor & &
\end{tabular}

SE: standard error, pT: pathological tumor.

prognosis (Table 3). The median value of GRP78 protein was $127.6 \mathrm{ng} / \mathrm{mL}$ for early-stage non-small cell lung cancer patients. Therefore, patients were divided into two groups (GRP78 value $>127.6 \mathrm{ng} / \mathrm{mL}$ and GRP78 value $\leq 127.6 \mathrm{ng}$ / $\mathrm{mL}$ ). Among the factors analyzed, age, gender, differentiation, pathological T, and GRP78 level were significant prognostic factors $(p=0.0052, p=0.0152, p=0.0113, p=0.0337$, and $p=0.0334$, resp., Table 3 ).

Five factors were subjected to multivariate analysis to identify independent prognostic factors: age, gender, differentiation, pathological T, and GRP78 level. The multivariate analysis revealed that gender, differentiation, and GRP78 level were three independent prognostic factors in these non-small cell lung cancer patients (Table 4).

3.5. Survival Analysis. Data from 74 patients were included in the survival analysis. The median follow-up time was 22.5 months for the entire cohort. The median RFS was 19 months for the 74 patients. The results indicated that the 1-, 2-, 3-, and 5-year survival rates for the 74 lung cancer patients were $90.14 \%, 79.33 \%, 70.79 \%$, and $64.35 \%$, respectively.

The results for the Kaplan-Meier survival curve analysis indicated that the patients with a higher GRP78 expression had shorter survival times compared with patients with a lower GRP78 expression (median overall survival, 39 versus 48.7 months) (RR: $0.3419,95 \%$ confidence interval (CI): $0.1272-0.9190 ; p=0.0334$ ) (Figure 1). However, the difference in relapse-free survival (RFS) between the low GRP78 expression $(\leq 127.6 \mathrm{ng} / \mathrm{mL})$ group and the high GRP78 expression $(>127.6 \mathrm{ng} / \mathrm{mL})$ group was not significant $(p=0.1585$, Figure 2).

\section{Discussion}

A robust induction of GRP78 occurs in many malignancies, including prostate cancer, breast cancer, hepatocellular

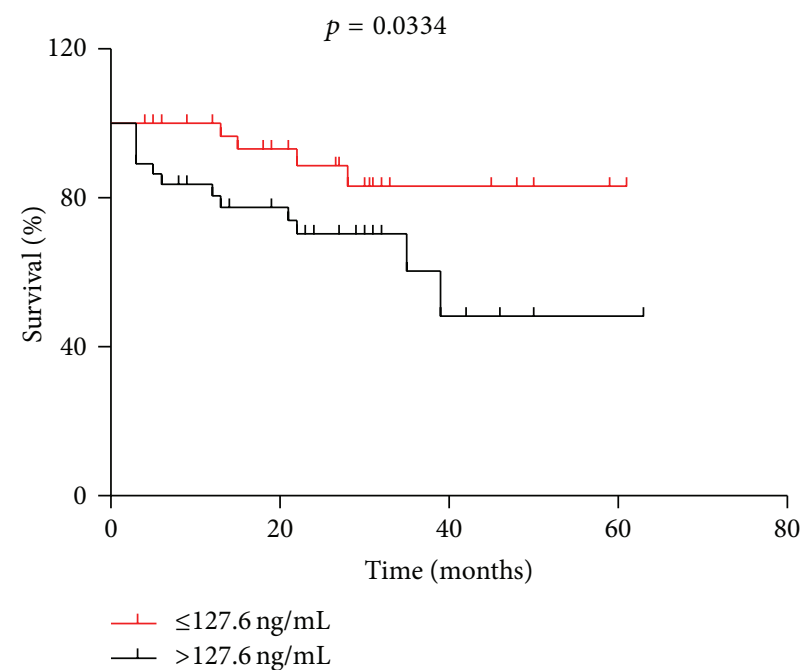

FIGURE 1: Kaplan-Meier survival curves for early-stage non-small cell lung cancer patients $(n=74)$, in relation to GRP78 protein expression. The survival of patients with higher GRP78 expression was significantly lower $(p=0.0334)$.

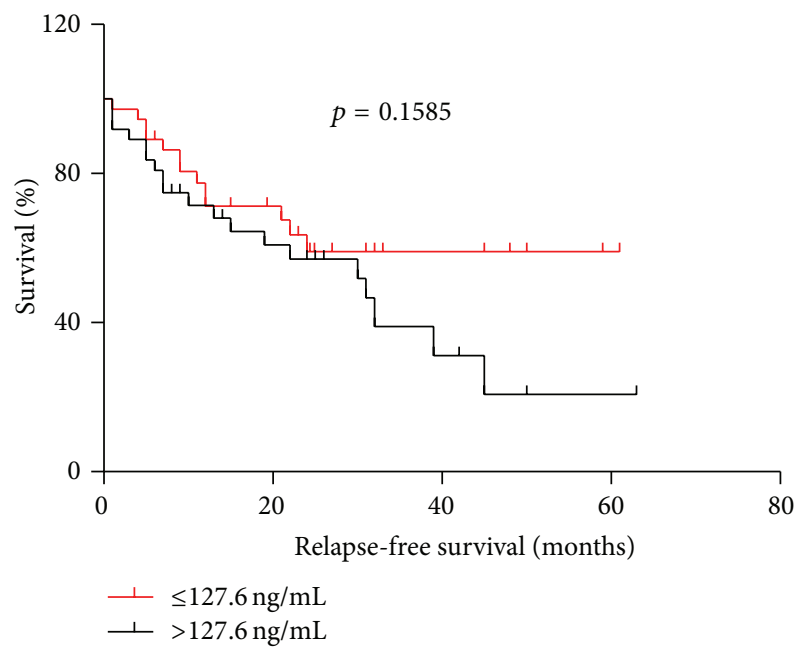

FIGURE 2: There were no significant differences in relapse-free survival (RFS) time between low GRP78 expression $(\leq 127.6 \mathrm{ng} / \mathrm{mL})$ and high GRP78 expression $(>127.6 \mathrm{ng} / \mathrm{mL})(p=0.1585)$ levels.

carcinoma, and colon cancer [14-17]. Recent studies demonstrate that GRP78 expression is correlated with poor prognosis in melanoma [18]. Wang et al. found that a high level of GRP78 is more common in patients with high-grade lung cancer [19]. Uramoto et al. reported that a positive expression of GRP78 is a significant factor that indicates a favorable prognosis [6]. The findings of Zheng et al. indicated that GRP78 is an effective and objective marker for aggressive behavior and poor prognosis in gastric carcinoma patients [20]. Controversy persists regarding the prognosis indicated by various GRP78 levels in malignancies. Until now, no studies have detected GRP78 in the serum of non-small cell lung cancer patients, the etiology of lung cancer is complex, and newer prognostic markers are needed for management 
TABLE 3: Prognostic factors for patients with early-stage non-small cell lung cancers $(n=74)$. Univariate analysis.

\begin{tabular}{|c|c|c|c|}
\hline \multirow{2}{*}{ Factor } & \multicolumn{2}{|c|}{ Univariate analysis } & \multirow{2}{*}{$p$ value } \\
\hline & $95 \% \mathrm{CI}$ & HR & \\
\hline Age ( $>60$ years versus $\leq 60$ years $)$ & $0.085-0.649$ & 0.235 & 0.0052 \\
\hline Gender (male versus female) & $1.273-9.565$ & 3.489 & 0.0152 \\
\hline Differentiation (well and moderate versus poor) & $1.336-9.653$ & 3.592 & 0.0113 \\
\hline pTNM stage after the surgery (stages I-II versus stage IIIa) & $0.229-1.816$ & 0.645 & 0.4064 \\
\hline $\mathrm{pT}(\mathrm{T} 1-2$ versus T3) & $0.0484-0.886$ & 0.207 & 0.0337 \\
\hline pN (N0 versus N1-2) & $0.265-1.924$ & 0.714 & 0.5114 \\
\hline GRP78 level $(\leq 127.6 \mathrm{ng} / \mathrm{mL}$ versus $>127.6 \mathrm{ng} / \mathrm{mL})$ & $0.127-0.919$ & 0.342 & 0.0334 \\
\hline
\end{tabular}

HR: hazard ratio, pTNM: pathological tumor-node-metastasis, pT: pathological tumor, pN: pathological node.

TABLE 4: Multivariate analysis results.

\begin{tabular}{|c|c|c|c|}
\hline Factor & $95 \% \mathrm{CI}$ & Risk ratio & $p$ value \\
\hline Age ( $>60$ years versus $\leq 60$ years) & $0.822-10.104$ & 2.88 & 0.098 \\
\hline Gender (male versus female) & $0.038-0.855$ & 0.181 & 0.031 \\
\hline Differentiation (well and moderate versus poor) & $0.046-0.629$ & 0.171 & 0.008 \\
\hline $\mathrm{pT}(\mathrm{T} 1-2$ versus $\mathrm{T} 3)$ & $0.161-1.488$ & 0.489 & 0.208 \\
\hline GRP78 level $(\leq 127.6 \mathrm{ng} / \mathrm{mL}$ versus $>127.6 \mathrm{ng} / \mathrm{mL})$ & $0.088-0.979$ & 0.294 & 0.046 \\
\hline
\end{tabular}

pT: pathological tumor.

of this lethal disease. We thus analyzed GRP78 expression in the serum of lung cancer patients and have provided results that indicate its potential as a prognostic biomarker for this serious malignant disease.

Compared with early-stage non-small cell lung cancers, we found significantly elevated levels of serum GRP78 expression in late-stage non-small cell lung cancers. This result was consistent with the results of Wang et al's study [19]. The regulation and expression of GRP78 have been associated with shorter overall survival times [21-23]. Our results were consistent with those of previous reports. High GRP78 expression may be a predictor of a shorter overall survival time.

Novel ER stress markers for drug responsiveness prediction are emerging as there has been an increasing recognition of an association between ER stress and human cancer, and an improved understanding of the diverse underlying molecular mechanisms [24]. GRP78 has been extensively documented to confer resistance against a wide range of therapies including chemotoxic drugs, antihormonal agents, DNA damaging agents, antiangiogenesis drugs, and chromatin-modifying drugs, as well as radiation therapy [25]. Several studies have shown that GRP78 conferred resistance against Adriamycinmediated apoptosis in cancer cells [26]. Jiang et al. suggested that knockdown of GRP78 can enhance the sensitivity of melanoma to chemotherapy drugs [27]; removing the tumor protection provided by ERS may enhance the sensitivity of chemotherapy drugs [28]. Roller and Maddalo found that GRP78 is often overexpressed in several types of cancers refractory to conventional therapy. GRP78 therefore may be not only a good biomarker to predict response to therapy, but also an appealing target for more selective chemotherapy approaches [29]. This may be one viable means of treating non-small cell lung cancer. However, a large group of patients with long-term follow-up is needed, and more cellular experiments should be performed, to confirm this conclusion. These approaches present exciting new opportunities for biological and clinical lung cancer research.

There were several limitations to our study that may have affected our results. First, this was a retrospective study. Second, the study sample size was small. Significant correlations with the clinicopathological parameters may have resulted if a greater number of patients had been included in the study. Third, we did not closely examine the response to chemotherapy and/or radiotherapy in the late-stage non-small cell lung cancer patients.

\section{Conclusion}

In conclusion, herein, our study was the first to detect the presence of GRP78 in serum of non-small cell lung cancer patients. The expression of GRP78 was highly enriched in the late-stage lung cancer patients and may be an important prognostic marker for non-small cell lung cancer. There were no significant correlations with clinicopathological parameters. Larger and more detailed follow-up studies will be required to confirm this finding and to determine if additional clinicopathological correlations with GRP78 expression can be identified. Future studies will be required to determine whether GRP78 levels can be used to guide the treatment of non-small cell lung cancer patients.

\section{Abbreviations}

GRP78: Glucose-regulated protein 78

BIP: Immunoglobulin heavy chain binding protein

ER: Endoplasmic reticulum 
ELISA: Enzyme-linked immune sorbent assay

TNM: Tumor-node-metastasis

OS: Overall survival

RFS: Relapse-free survival.

\section{Conflict of Interests}

The authors declare that they have no competing financial interests.

\section{Authors' Contribution}

Hecheng Li and Jiaqing Xiang conceived and designed the study. Su Yang collected all the specimens and coordinated the study. Xiaoli Zhu participated in the design of the study and gave suggestions to pathological research. Xiao Ma and Wei Guo coordinated the study, carried out the analyses, and wrote the paper. Su Yang was involved in statistical analysis. All authors have read and approved the final paper. Xiao $\mathrm{Ma}$ and Wei Guo contributed equally to this work.

\section{Acknowledgments}

This work was supported by grants from the Shanghai RisingStar Program (11QH1400600) and the National Natural Science Foundation of China (81272608 and 81102044).

\section{References}

[1] A. Jemal, F. Bray, M. M. Center, J. Ferlay, E. Ward, and D. Forman, "Global cancer statistics," CA Cancer Journal for Clinicians, vol. 61, no. 2, pp. 69-90, 2011.

[2] M. Sant, T. Aareleid, F. Berrino et al., "EUROCARE-3: survival of cancer patients diagnosed 1990-94-results and commentary," Annals of Oncology, vol. 14, supplement 5, Article ID 199094, pp. v61-v118, 2003.

[3] G. Korpanty, E. Smyth, and D. N. Carney, "Update on antiangiogenic therapy in non-small cell lung cancer: are we making progress?" Journal of Thoracic Disease, vol. 3, no. 1, pp. 19-29, 2011.

[4] M. J. McKeage, M. B. Jameson, and AS1404-201 Study Group Investigators, "Comparative outcomes of squamous and nonsquamous non-small cell lung cancer (NSCLC) patients in phase II studies of ASA404 (DMXAA) - retrospective analysis of pooled data," Journal of Thoracic Disease, vol. 2, no. 4, pp. 199-204, 2010.

[5] E. Shash, F. A. Peccatori, and H. A. Azim Jr., "Optimizing the use of epidermal growth factor receptor inhibitors in advanced non-small-lung cancer (NSCLC)," Journal of Thoracic Disease, vol. 3, no. 1, pp. 57-64, 2011.

[6] H. Uramoto, K. Sugio, T. Oyama et al., "Expression of endoplasmic reticulum molecular chaperone Grp78 in human lung cancer and its clinical significance," Lung Cancer, vol. 49, no. 1, pp. 55-62, 2005.

[7] M. Ni, Y. Zhang, and A. S. Lee, "Beyond the endoplasmic reticulum: atypical GRP78 in cell viability, signalling and therapeutic targeting," Biochemical Journal, vol. 434, no. 2, pp. 181-188, 2011.

[8] J. Kern, G. Untergasser, C. Zenzmaier et al., "GRP-78 secreted by tumor cells blocks the antiangiogenic activity of bortezomib," Blood, vol. 114, no. 18, pp. 3960-3967, 2009.
[9] G. Bánhegyi, P. Baumeister, A. Benedetti et al., "Endoplasmic reticulum stress," Annals of the New York Academy of Sciences, vol. 1113, pp. 58-71, 2007.

[10] Y. Kimata and K. Kohno, "Endoplasmic reticulum stresssensing mechanisms in yeast and mammalian cells," Current Opinion in Cell Biology, vol. 23, no. 2, pp. 135-142, 2011.

[11] Y. Fu and A. S. Lee, "Focused eeview: ER stress and cancer glucose regulated proteins in cancer progression, drug resistance and immunotherapy," Cancer Biology \& Therapy, vol. 5, no. 7, pp. 741-744, 2006.

[12] Q. J. Quinones, G. G. de Ridder, and S. V. Pizzo, "GRP78, a chaperone with diverse roles beyond the endoplasmic reticulum," Histology and Histopathology, vol. 23, no. 11, pp. 1409-1416, 2008.

[13] S. Edge, D. Byrd, C. Compton et al., American Joint Committee on Cancer, American Cancer Society: AJCC Cancer Staging Manual, vol. 41, Springer, New York, NY, USA, 2010.

[14] S. Daneshmand, M. L. Quek, E. Lin et al., "Glucose-regulated protein GRP78 is up-regulated in prostate cancer and correlates with recurrence and survival," Human Pathology, vol. 38, no. 10, pp. 1547-1552, 2007.

[15] P. M. Fernandez, S. O. Tabbara, L. K. Jacobs et al., "Overexpression of the glucose-regulated stress gene GRP78 in malignant but not benign human breast lesions," Breast Cancer Research and Treatment, vol. 59, no. 1, pp. 15-26, 2000.

[16] Q. Shao, P. Ren, Y. Li et al., "Autoantibodies against glucoseregulated protein 78 as serological diagnostic biomarkers in hepatocellular carcinoma," International Journal of Oncology, vol. 41, no. 3, pp. 1061-1067, 2012.

[17] H. Takahashi, J.-P. Wang, H.-C. Zheng, S. Masuda, and Y. Takano, "Overexpression of GRP78 and GRP94 is involved in colorectal carcinogenesis," Histology and Histopathology, vol. 26, no. 6, pp. 663-671, 2011.

[18] M. Guan, X. Chen, Y. Ma et al., "MDA-9 and GRP78 as potential diagnostic biomarkers for early detection of melanoma metastasis," Tumor Biology, vol. 36, no. 4, pp. 2973-2982, 2015.

[19] Q. Wang, Z. He, J. Zhang et al., "Overexpression of endoplasmic reticulum molecular chaperone GRP94 and GRP78 in human lung cancer tissues and its significance," Cancer Detection and Prevention, vol. 29, no. 6, pp. 544-551, 2005.

[20] H.-C. Zheng, H. Takahashi, X.-H. Li et al., "Overexpression of GRP78 and GRP94 are markers for aggressive behavior and poor prognosis in gastric carcinomas," Human Pathology, vol. 39, no. 7, pp. 1042-1049, 2008.

[21] K. Kuroda, A. Horiguchi, T. Asano et al., "Glucose-regulated protein 78 positivity as a predictor of poor survival in patients with renal cell carcinoma," Urologia Internationalis, vol. 87, no. 4, pp. 450-456, 2011.

[22] K. Matsuo, M. J. Gray, D. Y. Yang et al., "The endoplasmic reticulum stress marker, glucose-regulated protein-78 (GRP78) in visceral adipocytes predicts endometrial cancer progression and patient survival," Gynecologic Oncology, vol. 128, no. 3, pp. 552-559, 2013.

[23] J. A. Papalas, R. T. Vollmer, M. Gonzalez-Gronow et al., "Patterns of GRP78 and MTJ1 expression in primary cutaneous malignant melanoma," Modern Pathology, vol. 23, no. 1, pp. 134143, 2010.

[24] Y.-Z. Zheng, Z.-G. Cao, X. Hu, and Z.-M. Shao, "The endoplasmic reticulum stress markers GRP78 and CHOP predict disease-free survival and responsiveness to chemotherapy in breast cancer," Breast Cancer Research and Treatment, vol. 145, no. 2, pp. 349-358, 2014. 
[25] A. S. Lee, "Glucose-regulated proteins in cancer: molecular mechanisms and therapeutic potential," Nature Reviews Cancer, vol. 14, no. 4, pp. 263-276, 2014.

[26] H.-Y. Tsai, Y.-F. Yang, A. T. Wu et al., "Endoplasmic reticulum ribosome-binding protein 1 (RRBP1) overexpression is frequently found in lung cancer patients and alleviates intracellular stress-induced apoptosis through the enhancement of GRP78," Oncogene, vol. 32, no. 41, pp. 4921-4931, 2013.

[27] C. C. Jiang, Z. G. Mao, K. A. Avery-Kiejda, M. Wade, P. Hersey, and X. D. Zhang, "Glucose-regulated protein 78 antagonizes cisplatin and adriamycin in human melanoma cells," Carcinogenesis, vol. 30, no. 2, pp. 197-204, 2009.

[28] F. Xia, J. C. Xu, P. Zhang et al., "Glucose-regulated protein 78 and heparanase expression in oral squamous cell carcinoma: correlations and prognostic significance," World Journal of Surgical Oncology, vol. 12, article 121, 2014.

[29] C. Roller and D. Maddalo, "The molecular chaperone GRP78/ $\mathrm{BiP}$ in the development of chemoresistance: mechanism and possible treatment," Frontiers in Pharmacology, vol. 4, article 10, 2013. 


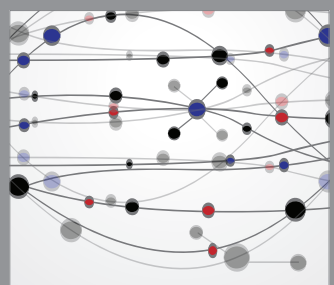

The Scientific World Journal
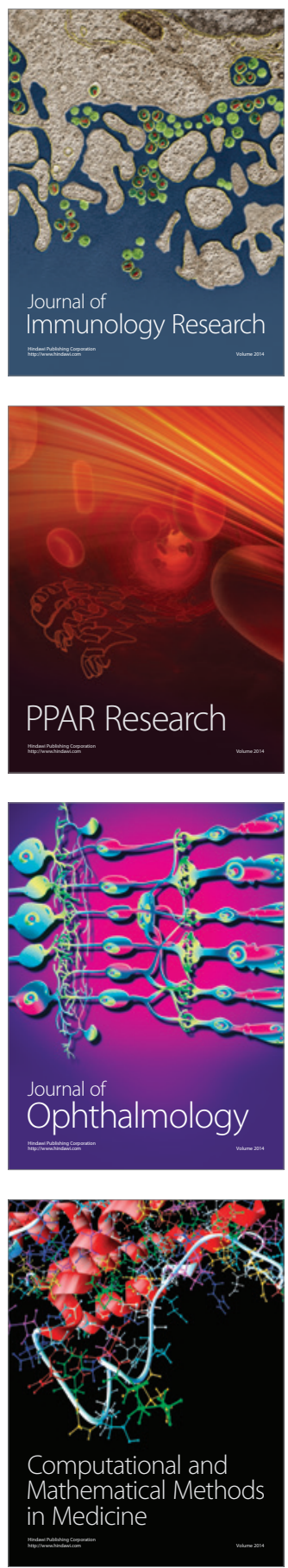

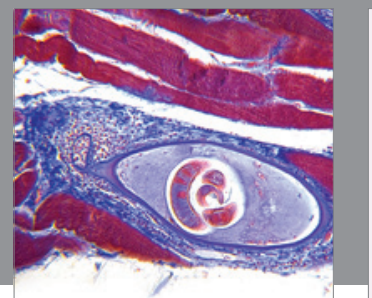

Gastroenterology

Research and Practice
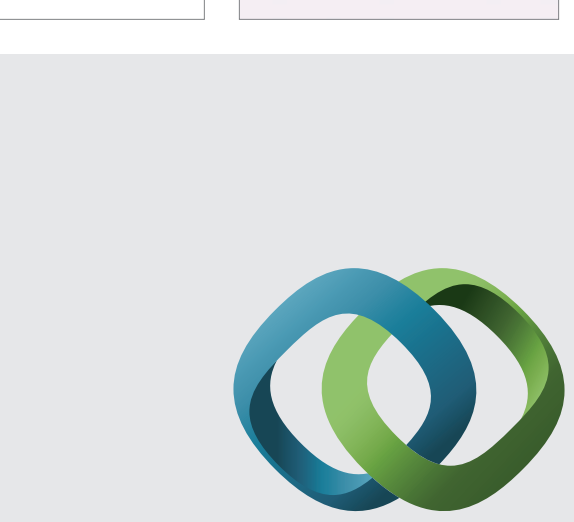

\section{Hindawi}

Submit your manuscripts at

http://www.hindawi.com
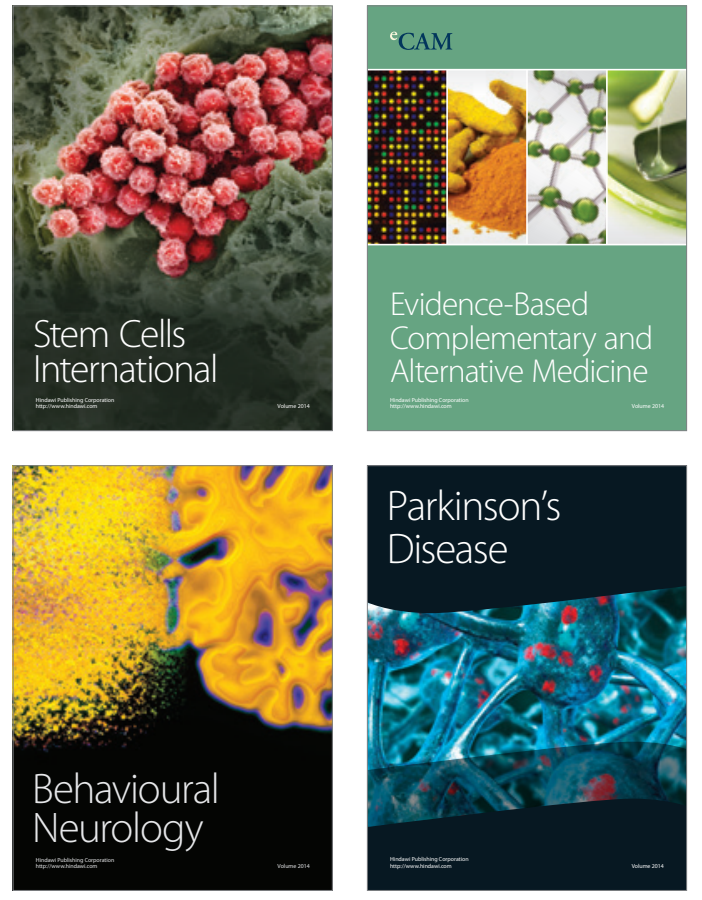
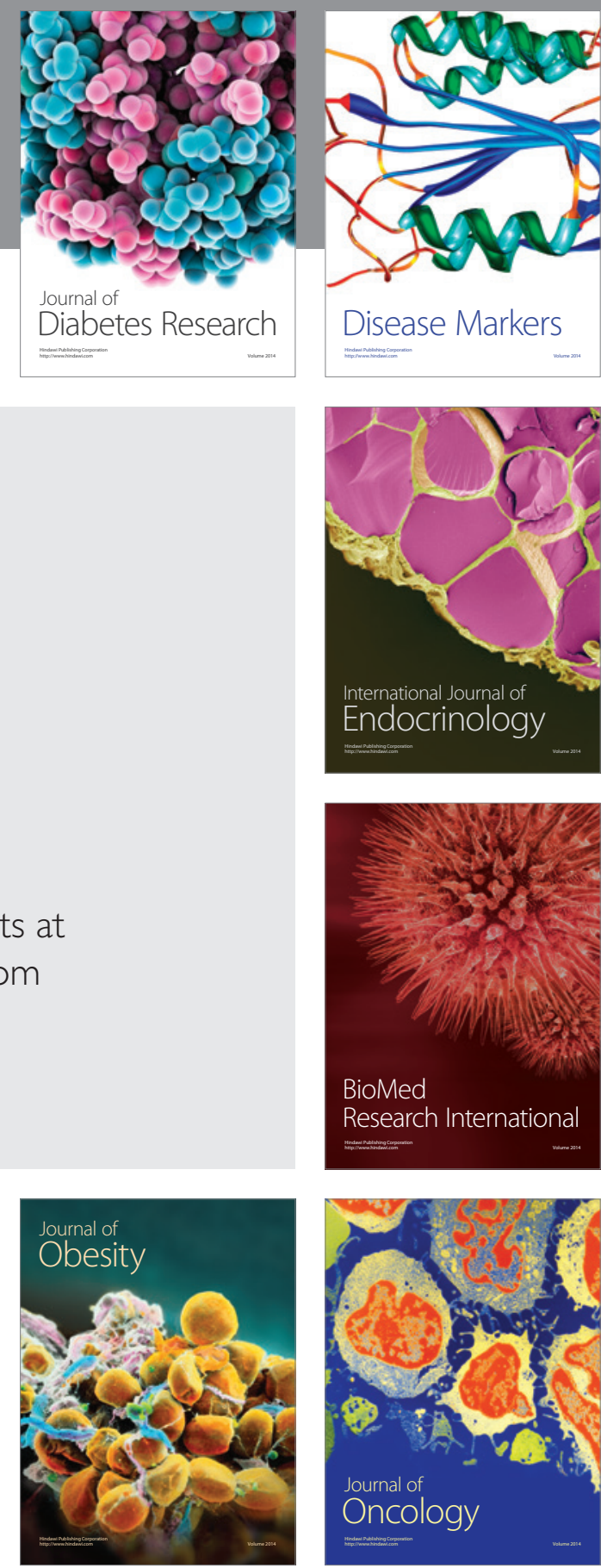

Disease Markers
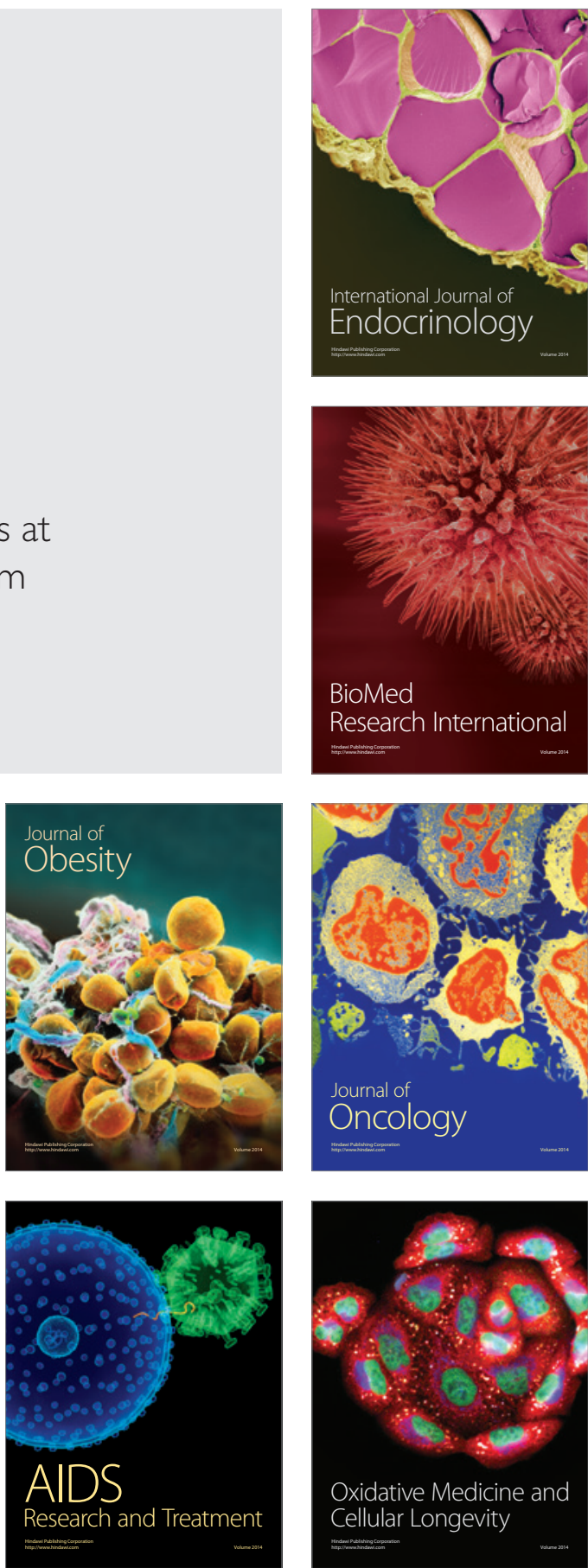